Article

\title{
On a Long Term Strategy for the Success of Nuclear Power
}

\author{
Bruno Merk 1,2,3,*, Dzianis Litskevich ${ }^{1}$, Karl R. Whittle ${ }^{1}$, Mark Bankhead ${ }^{2}$, Richard J. Taylor ${ }^{4}$ \\ and Dan Mathers 2
}

1 School of Engineering, University of Liverpool, Liverpool L69 3GH, UK; d.litskevich@liverpool.ac.uk (D.L.); krw72@liverpool.ac.uk (K.R.W.)

2 National Nuclear Laboratory, Chadwick House, Warrington WA3 6AE, UK; mark.bankhead@nnl.co.uk (M.B.); richard.taylor-4@manchester.ac.uk (R.J.T.); daniel.p.mathers@nnl.co.uk (D.M.)

3 Helmholtz-Zentrum Dresden-Rossendorf (HZDR), Bautzner Landstraße 400, 01328 Dresden, Germany

4 School of Mechanical Aerospace \& Civil Engineering, The University of Manchester, Manchester M1 3BB, UK; richard.taylor-4@manchester.ac.uk

* Correspondence: b.merk@liverpool.ac.uk; Tel.: +44-151-794-5370

Received: 7 April 2017; Accepted: 22 June 2017; Published: 28 June 2017

\begin{abstract}
The current generation of nuclear reactors are evolutionary in design, mostly based on the technology originally designed to power submarines, and dominated by light water reactors. The aims of the Generation IV consortium are driven by sustainability, safety and reliability, economics, and proliferation resistance. The aims are extended here to encompass the ultimate and universal vision for strategic development of energy production, the "perpetuum mobile"-at least as close as possible. We propose to rethink nuclear reactor design with the mission to develop an innovative system which uses no fresh resources and produces no fresh waste during operation as well as generates power safe and reliably in economic way. The results of the innovative simulations presented here demonstrate that, from a theoretical perspective, it is feasible to fulfil the mission through the direct reuse of spent nuclear fuel from currently operating reactors as the fuel for a proposed new reactor. The produced waste is less burdensome than current spent nuclear fuel which is used as feed to the system. However, safety, reliability and operational economics will need to be demonstrated to create the basis for the long term success of nuclear reactors as a major carbon free, sustainable, and applied highly reliable energy source.
\end{abstract}

Keywords: nuclear; reactor; spent fuel; P\&T; innovation strategy; molten salt reactor

\section{Introduction}

Strategic development is the key to the success of industrial innovation in the long term. The final outcome differs very often significantly from the objectives given at begin of the development, since external drivers like political, economic or technical boundary conditions change with time. Already in the 1960s, Everett Rogers described the development of innovation through S-curves and formulated this effect in the theory of diffusion of innovations [1]. Rogers' argues that the application of a technology to a market and the penetration phases from low to high follow an S-curve which is characterized by innovators and early adopters in the first phases and laggards joining the development at the end.

However, Fredmund Malik extended this thinking calling it a "Symphony of S-curves: Seeing the Future Clearly" in his book on strategy development [2] to motivate the people to leave the track of purely evolutionary development when it is indicated by changed boundary conditions. He argues that evolutionary development slows down significantly when the market is saturated. The development 
speed can only be kept in this phase when a disruption in development appears which creates a new technology entering in to a new phase of rapid development. In this case strategic development enters into a new S-curve. In a first step this concept will be used to derive a deeper understanding of the idea of strategic development of industrial innovations applying an excursion to a day-to-day issue. In a second step the concept is applied to analyze the current development of nuclear reactor systems. The historic boundary conditions are reviewed against the current boundary conditions and the pace of development. The updated boundary conditions will be used to define a reactor system which is as close as possible to the requirements for a wide spread future electric energy production using nuclear power. This is a major request to create the basis for the long term success of nuclear reactors to act as a major contributor for the production of reliable carbon free, sustainable electric energy. Finally, theoretical thinking is complemented with a reactor physical simulation demonstrating the feasibility of the proposed solution from physical point of view.

\section{Excursion: "The Lawn Mower Problem"}

The beginning of the lawn mower problem goes back to 1830 when the first lawn mower was developed/invented [3]. This date marks the step from cutting grass by hand to using an automated system. Over the subsequent 200 years diverse optimized solutions have been developed. These developments follow the aim making the work easier (see Figure 1). We have almost approached the end of this curve with the characteristic very low development speed. The most recent development of robot lawn mowers mark the change from the first, black to the second S-curve (red) new, more sophisticated objectives and changed technical as well as legal boundary conditions.

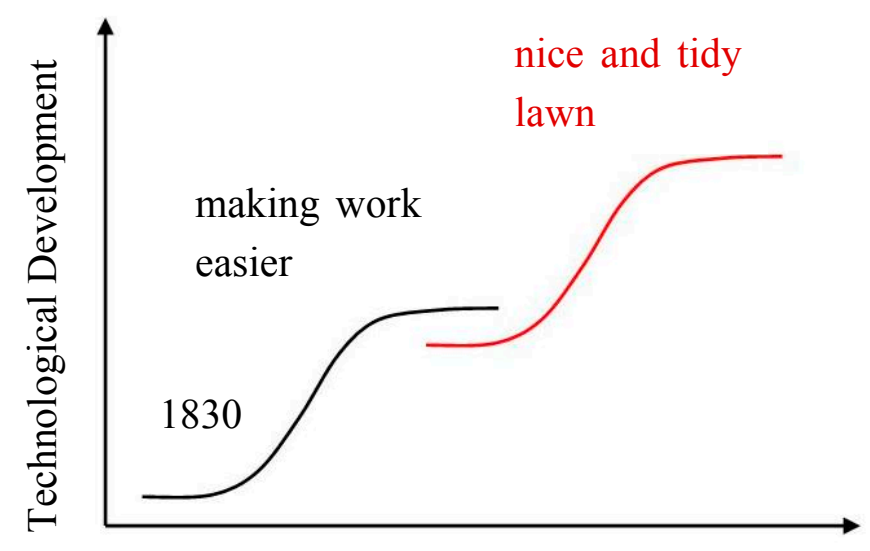

Development with Time

Figure 1. The lawn mower development in S-curves.

From strategic development point of view, the objective of the first S-curve "make the work easier" has changed to "I want a nice tidy garden lawn, ideally without spending any work and money". The robot is the first step into the red curve-reducing hand work. However, there could appear other more innovative solutions like genetic manipulated, or even artificial grass. The use of slaves isn't possible due to changed legal boundary conditions. Ideally, the tidy garden lawn should be achieved without cost for energy, equipment, and work time-this we could call the vision, or "dream" solution. The best solution could come as close as possible but will never fulfil the vision completely.

The development of nuclear reactors has followed an evolutionary track of both the technical solution and the question the technology is trying to address. Thus, we propose to address the future strategic development of nuclear reactors by moving to a new, more advanced S-curve to be able to define a new vision which is addressing the changed boundary conditions. In the following chapters we will develop a long term strategy for the success of nuclear power starting with a very broad and 
general view on strategic development like in the excursion above. This is started by an analysis of the historic development and the analysis of the historic development objectives followed by applying tools of strategic development, to come up with a new, general vision and a possible mission. This analysis on a higher system level provides a more wide and systematic view than thinking in the level of the development of current project, "to look further into the future and capture a longer period of time which is indispensable for strategy development, a typical cybernetic approach is useful: the change of system levels" [2]. To avoid the critics being dreamers, we have developed one example to prove the most challenging neutron physical feasibility of our proposal of operating a reactor on spent nuclear fuel. This example should not be seen as exclusive, it should motivate the community to develop several systems fulfilling the vision ideally even for different missions arising from different applications for nuclear reactors. What we propose here would be a significant progress compared to all current operational regimes of nuclear reactors. It is the ultimate step to use spent nuclear fuel directly without any prior reprocessing. The feasibility study is followed by a broad discussion of the consequences of our proposal, partly based on the simulation results, partly based on the specific opportunities of the proposed reactor system. We close with a view onto the challenges and the requests to make this proposal successful.

\section{Development of Nuclear Reactor Technologies}

\subsection{Historic Development}

The development of nuclear reactors started in war times in 1942, with development of Chicago Pile 1, the world's first nuclear reactor, built by Nobel Prize winner Enrico Fermi [4]. During the first years of development, the purpose of a nuclear reactor was based around three objectives:

1. Demonstration of a continuing chain reaction and its potential application

2. Generation of material for military purposes and/or commercial/medical applications

3. Energy generation from the chain reaction, either as electricity, most desirable, or heat

The main focus of reactors today is the generation of energy, i.e., objective 3. However, even objective 3 has undergone a partial change given by the request for a solution for the energy trilemma. The request is developing the energy technologies toward the objectives of energy security, energy equity (accessibility and affordability), and environmental sustainability [6]. The safe use of the chain reaction has been extensively proven and the production of medical isotopes is secured using more specialized technologies. After the following theoretical discussion about the historic and the possible future technological development and the change of the vision, we will describe a highly innovative reactor system which has the potential for a disruptive innovation in nuclear energy production. This will be followed by the demonstration of the neutron physical feasibility of a reactor with significantly improved sustainability indices.

Going back to the begin of the development, "In the course of developing nuclear weapons the Soviet Union and the West had acquired a range of new technologies and scientists realized that the tremendous heat produced in the process could be tapped either for direct use or for generating electricity [7]". This quote characterizes the origin of nuclear power production, heat and the use of technologies to transform the heat to electricity has been seen as a by-product created when fulfilling objective 2 (producing material for military purposes). Besides this, the early development was driven by the request for a compact long-lasting power source for submarines under Admiral Rickover in his function as Director of the Naval Reactors Branch [8] leading to the first nuclear-powered submarine, the USS Nautilus. The first nuclear reactor for electricity production was EBR- 1 a sodium-potassium cooled fast reactor in the US, a system which is ideal for the production of plutonium. A major step for the civil nuclear energy development was the "Atoms for Peace" program [9] linked with the name of the US President Eisenhower, the foundation of the IAEA, and the words "The United States knows that peaceful power from atomic energy is no dream of the future. The capability, already proved, 
is here today" [10] spoken at the 470th Plenary Meeting of the United Nations General Assembly on 8 December 1953. "When President Eisenhower delivered his Atoms for Peace speech ... , it marked a transition toward a broader spectrum of potential applications of this new source of power. This shift led first to nuclear-powered submarines and ultimately to land-based nuclear power plants based on a scaled-up version of the submarine-designed water-cooled reactor" [11]. The first nuclear reactor producing a significant amount of electricity was the Russian AM-1 reactor which was water-cooled and graphite-moderated, once more an ideal configuration for plutonium production. In Russia, it was followed by a lead-bismuth reactor for the navy and a program for the development of sodium cooled fast reactors which offer long cycle times due to breeding of plutonium. In parallel development of the pressurized water reactor (PWR) has been driven by the US navy leading to the USS Nautilus and later to the stationary Shippingport reactor with an initial output of 60 MWe built in 1957 in the search of a robust and easy to operate system. An alternative design based on the use of molten salt as coolant, innovatively designed to power air travel, was built in 1954, which in turn led to the molten salt reactor experiment at Oak Ridge National Laboratory in 1965 [7].

In 1956 the first commercial reactor, the gas-cooled MAGNOX reactor at Calder Hall, started operating [7]. One of the aspects of the MAGNOX design was the output of weapon grade plutonium, which in turn provided a secondary income for the operators, due to the government buying back the formed plutonium. The reprocessing in the UK was developed around this need. "In their early years (1963-1972) the UK's civil Magnox reactors produced significant amounts of weapons-grade plutonium, British Nuclear Fuels Ltd. admitted that they called the weapons-grade plutonium "military" irrespective of origin" [12]. The Pu has been given to the United States in exchange for fissile material for UK military requirements [13]. The follow up system, the AGR would have been attractive for high quality Pu production, too. However, due to the already changed demand the reactors have never been operated in an optimized way for plutonium production, but heavily for electricity production.

Comparable design principles like for the MAGNOX system, graphite moderation and natural uranium as fuel, with online refueling characterize the RBMK reactors "derived from a design principally for plutonium production and was intended and used in Russia for both plutonium and power production" [14].

However, not only reactor development but also the reprocessing of nuclear material can be followed back to war times. "The roots of nuclear reprocessing also are found in that same realm of war and commercial technology (like the reactor technology). After Seaborg and coworkers discovered plutonium, it was quickly established as an alternative pathway to nuclear weapons that could be built around nuclear reactors and chemical reprocessing" [11]. Nevertheless, both technologies (reactor and reprocessing) have been developed significantly forward for the civil application. The described first generation of reactors development has continued leading to further generations, mainly of commercial light water power reactors, see Figure 2. The current generation of reactors are the Generation III and III+, once more evolutionary designs. The market for nuclear reactors for energy production is currently almost completely dominated by industrially applied Light Water Reactors (LWRs) while the industrial reprocessing is built on the so-called aqueous technology.

Today, the military application is less attractive to most countries. It is even turned around to the demand of proliferation resistance for nuclear systems. It is politically desirable for most of the world's nations to maintain obligations under strategic nuclear disarmament treaties and focus on the peaceful development of nuclear power supplying safe and sustainable low carbon energy. Following this desire the next generation of nuclear reactors currently under development are following the goals outlined by the Generation IV International Forum (GIF), see Figure 3. More details on the specific reactor systems and the related fuel cycles can be found in [15]. 


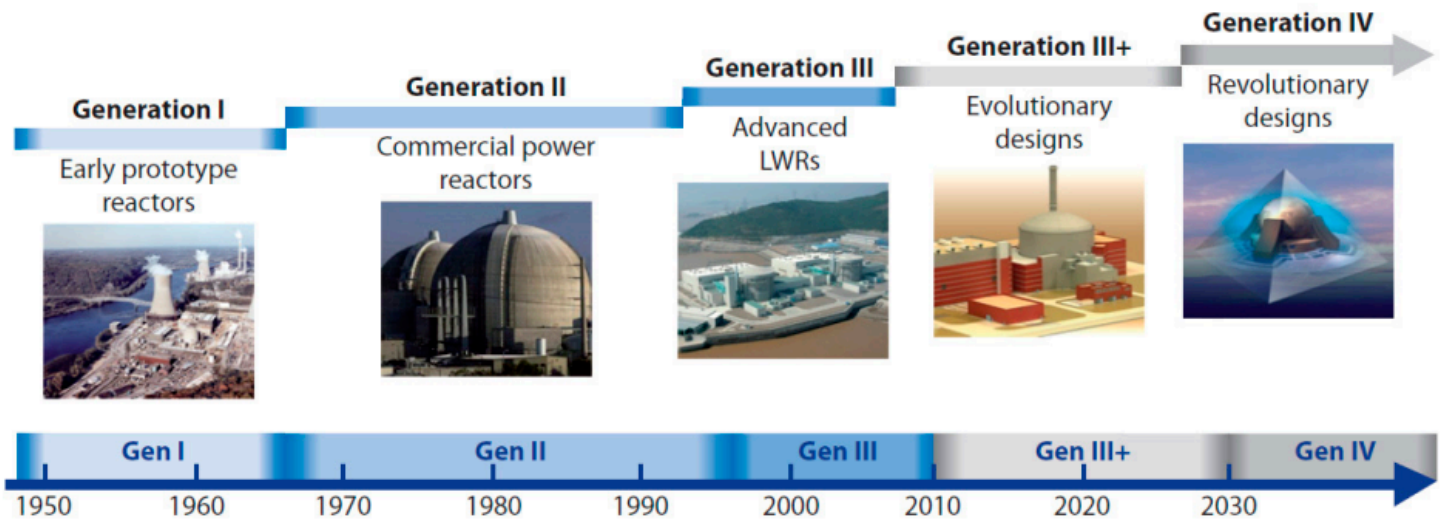

Figure 2. Generations of nuclear power: Time ranges correspond to the design and the first deployments of different generations of reactors [5].

\section{Sustainability}

- Generate energy sustainably and promote long-term availability of nuclear fuel.

- $\quad$ Minimise nuclear waste and reduce the long term stewardship burden.

Safety and reliability

- $\quad$ Excel in safety and reliability.

- Have a very low likelihood and degree of reactor core damage.

- $\quad$ Eliminate the need for offsite emergency response.

Economics

- Have a life cycle cost advantage over other energy sources.

- Have a level of financial risk comparable to other energy projects.

Proliferation resistance and physical protection

- $\quad$ Be a very unattractive route for diversion or theft of weapon-usable materials, and provide increased physical protection against acts of terrorism.
- $\quad$ gas-cooled fast reactor (GFR)

- lead-cooled fast reactor (LFR)

- molten salt reactor (MSR)

- $\quad$ sodium-cooled fast reactor (SFR)

- supercritical-watercooled reactor (SCWR)

- very-high-temperature reactor (VHTR)

Figure 3. Generation IV (GenIV) goals (left) and GenIV systems (right) [5].

\subsection{Strategic Development for the Future}

The given Gen IV goals build the bridge between the current S-curve and the future one to support a new vision, see Figure 4 . The current light water reactors are still essentially based on technology used to power nuclear submarines, even if they have undergone an evolution via Generation II to Generation III/III+ reactors. The reactors are to be seen as the current ideal. The Gen IV program is the foreseen next stage of reactor design applying 'new, innovative' concepts for nuclear power generation. Such concepts could lead to a reactor that can continually breed, and burn its own fuel, i.e., become a perpetual reactor with significantly lower demand for fresh fuel like current light water reactors. Thus, closed fuel cycle operation is one, but not the only, major development direction to improve sustainability of nuclear reactor operation following the Gen IV objectives [16]. Closing the nuclear fuel cycle has already been discussed since decades and the results have been documented in several publication of the OECD Nuclear Energy Agency (NEA) [17] and the International Atomic Energy Agency (IAEA) [18]. However, the complexity of the challenge in reprocessing and fuel production has to be recognized, see later discussion. Due to the wide operational experience of more than 400 reactor operation years, the sodium cooled fast reactor technology seems to be the one closest to application [19]. 


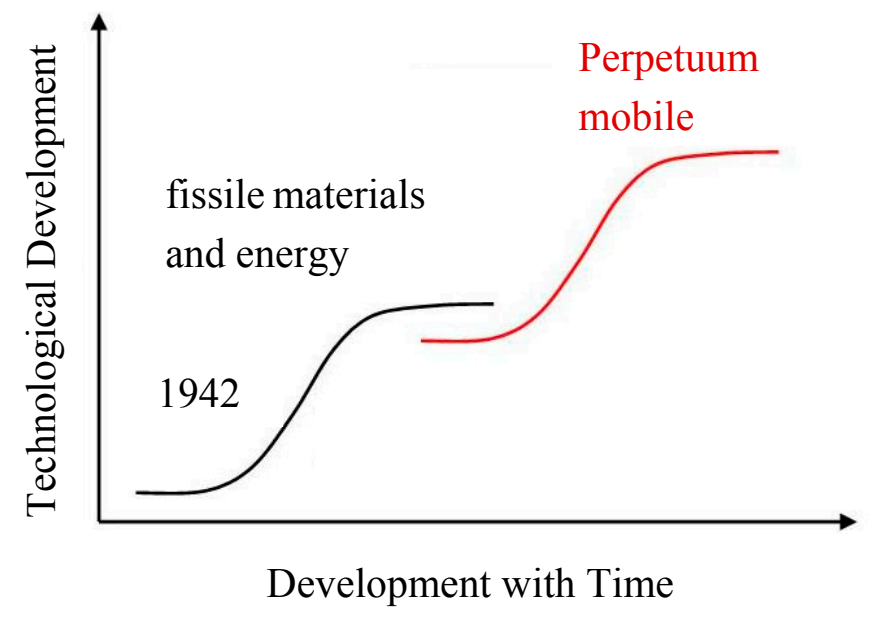

Figure 4. The nuclear reactor development in S-curves.

However, seen from the historic point of view given above, almost all systems are based on the very early developments of nuclear reactors with objectives formed by completely different boundary conditions and requests as we have it today-producing nuclear materials and powering submarines versus wide spread, sustainable, low carbon power production by nuclear reactors. Some important decisions on the way have been made on the historic requests to develop the ideal system for plutonium production. A perfect example is the decision between the molten salt breeder reactor and the sodium cooled fast reactor [20]. A sodium cooled reactor with solid fuel is advantageous for the production of high quality plutonium but will it be advantageous for the wide spread sustainable power production, too?

Applying the future request of wide spread sustainable power production defined by the "energy trilemma", the upcoming next level S-curve should lead to the ultimate, universal vision for energy production (independent of the observed "power plant" system). This vision is much more broad and advanced than the development goals of the first reactors and even more advanced and broad than the Gen IV goals. This ultimate, universal vision can be given with one simple, old phrase-“perpetuum mobile". Malik characterizes the function of the vision from the view of strategy development and strategic development point of view in the following way: "A mission is definitely necessary (for the strategy development), and I will get to that shortly. It often follows from a very broad and far-reaching idea which could be called a vision or a dream. That dream, however, has to be transformed into a viable mission: this is the only way to distinguish useful from useless visions" [2].

It is a clear consensus, amongst physicists and engineers, there is the first law of thermodynamics that prevents a perpetuum mobile from operating-thus it is a dream. However, it provides a clear vision and a far-reaching goal that has to drive research and innovation. The key words for the vision are:

- No resources requested

- No waste produced

- Highly economic, reliable, safe and secure

In the next step of strategic development, the transformation of the very general vision to a viable mission has to be given. The mission derived from the given vision could be, to develop a reactor that can breed and burn its own fuel, for significant period of time and solve the waste problem in addition. This can be seen as a viable mission which brings us as close as possible to the vision which is the essential basis for a successful wide spread application of nuclear reactors. The mission should be fulfilling the requests to form the basis for the successful future of nuclear energy production to become nuclear a worldwide recognized and applied technology as a major reliable, low carbon, and sustainable energy source. In more detail, the vision of the "perpetuum mobile" could be translated to 
the viable mission following ideal postulates but now lining it to a possible really operable nuclear reactor conception.

Obviously, a reactor can't be operated without resources but it would be a smart mission to better use already existing resources which are currently characterized as waste. A reactor could be designed which doesn't require fresh resources, i.e., it can be operated with spent nuclear fuel (SNF) from light water reactors which exists in vast amounts, see below. This kind of reactor design should not produce additional waste, i.e., the waste should closely match the SNF which is used to fuel the reactor, but a significantly increased amount of energy would be produced out of this already existing resource. Ideally, the long term activity of the nuclear waste mainly caused by the transuranium elements could be eliminated, too. Designing this kind of fuel cycle could be seen as an evolution of the first ideas of reusing spent fuel from light water reactors in heavy water moderated reactors [21]. However, the proposed approach is much wider since the re-use of solid fuel in a heavy water reactor has, due to criticality reasons, only the potential to release an increased fraction of the energy compared to a light water reactor.

The design should also make misuse of the plutonium as unattractive as possible, i.e., reduce the likelihood of further nefarious use of plutonium. This could be achieved through many routes, but at least one should be incorporated in the reactor design. The reactor or in a more global view the whole nuclear system has to be designed in a way to be at least as economic as current technologies (nuclear as well as non-nuclear). Additionally, the system has to be highly reliable and secure to operate and remain a safe technology.

The sustainability of long term operation on spent nuclear fuel defined above has to be solved within the core physics of the reactor, as well as the inclusion of a Pu vector preventing any misuse of the $\mathrm{Pu}$. Such a system can only be achieved once the system can provide enough neutrons for a self-sustained operation on the basis of SNF used, directly impacting the choice of the Pu vector.

The following feasibility study is based on a molten salt fast reactor configuration which will need further optimization to realize all the requested goals. One of the key points leading to the decision to investigate molten salt reactor technology is given in the Nuclear Fuel Cycle Evaluation and Screening of the United States [22]. Especially, in the Mass Flow Data Comparison details of the study indicating that Molten Salt Reactors (MSRs) have the potential for the highest (fissile material) utilization which result in the lowest material losses [23]. The potential advantageous safety behavior and the excellent operational flexibility have already been extensively discussed [24-26] for molten salt fast reactors. The challenges in the implementation of molten salt reactors have already been described in several projects $[27,28]$. A detailed list of $R \& D$ challenges is given in a final paragraph highlighting the demand of a research program.

\section{Results}

\subsection{Initial Core}

The initial core configuration for the simulation is based on the starting configuration with $65 \%$ $\mathrm{mol} \mathrm{LiF}, 28.4 \% \mathrm{~mol} \mathrm{SNF}$, and $6.6 \% \mathrm{~mol}$ Transuranium Isotopes (TRU), translating to $62 \mathrm{t}$ of SNF with $15 \mathrm{t}$ of TRU which accumulates to $74 \mathrm{t}$ of heavy metal (HM), with the blanket filled with pure LiF salt. Such a configuration leads to a start-up core with an averaged $\Delta \overline{k e f f}$ of 0 over the first burnup cycle of $5 \mathrm{GWd} / \mathrm{tHM}$.

\subsection{Simulation over Lifetime}

For the simulation over longer term variable TRU feeding is used to keep the $\Delta$ keff in the range of $\pm 400 \mathrm{pcm}$, Figure 5. In the initial phase, at least until the first tip $\sim 0.75 \%$ of the initial loading is fed in every calculation cycle. In the later stage between the two tips the feeding is reduced to $\sim 0.25 \%$. Over the whole TRU feeding period $\sim 3.6 \mathrm{t}$ of TRU are fed into the system within nearly 20 years. Additionally, a constant amount of SNF is fed into the system to keep the U-238 level almost 
constant. After reaching a balanced system, the TRU feed is not needed anymore. The system becomes self-sustainable after $\sim 18.5$ years, from this point only SNF is fed into the system. Over the evaluated operational period of 60 years $68.3 \mathrm{t}$ of SNF are fed into the system, accounting for the macron TRU feed, too, about $69 \mathrm{t}$ of heavy metal are fed.

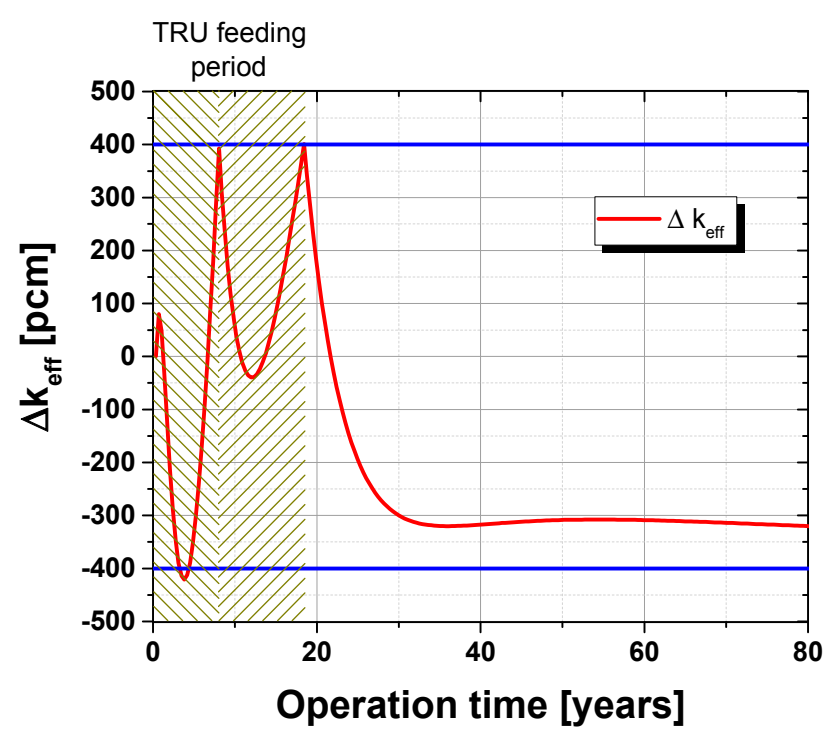

Figure 5. Change of the deviation of the averaged effective multiplication factor $\Delta$ keff over a simulated operational period of 80 years within the iteration band of $\pm 400 \mathrm{pcm}$.

\subsection{Isotopic Contents}

Throughout the observed period, the atomic number density of U-238 remains almost constant (within $0.6 \%$ ), with the U-238 content in the core rising slowly during the first $\sim 20$ years and reducing over the remainder of the operational period. This small change arises from the TRU feeding which changes the breeding balance slightly. Once there is no TRU feed anymore, slightly more U-238 is consumed by capture reactions leading to the breeding of fresh plutonium.

The atomic number density of the most important fissile isotope Pu-239 increases during the first part of the TRU feeding period, as shown in Figure 6. Once the second stage of reduced TRU feed is reached, the $\mathrm{Pu}-239$ content remains fairly constant, with the $\mathrm{Pu}-239$ content decreasing to an asymptotic value once TRU feeding is stopped. However, the Pu-240 content in the core increases to an asymptotic value almost twice the initial value, whereas the Pu-241 content drops during TRU feeding below the initial amount produced within the LWR, even after this amount has already been reduced to half simulating the long term storage of SNF. Both Pu-242, and Pu-238 content increases during TRU feeding, with both values decreasing during operation.

Isotopic analysis of the $\mathrm{Pu}$ compositions at the end of the model operation shows dramatic changes, when compared to the initial TRU feed, see Table 1. The share of LWR fissile Pu isotopes decreases from the already low content of TRU in the high burnup LWR fuel. The primary cause is significant build-up of Pu-240, see Figure 6, with the observed decrease of Pu-241 and 242, which is itself typical for the operation of a nuclear reactor with a fast neutron spectrum, where the accumulation of higher isotopes is strongly reduced compared to LWR with thermal spectrum. 


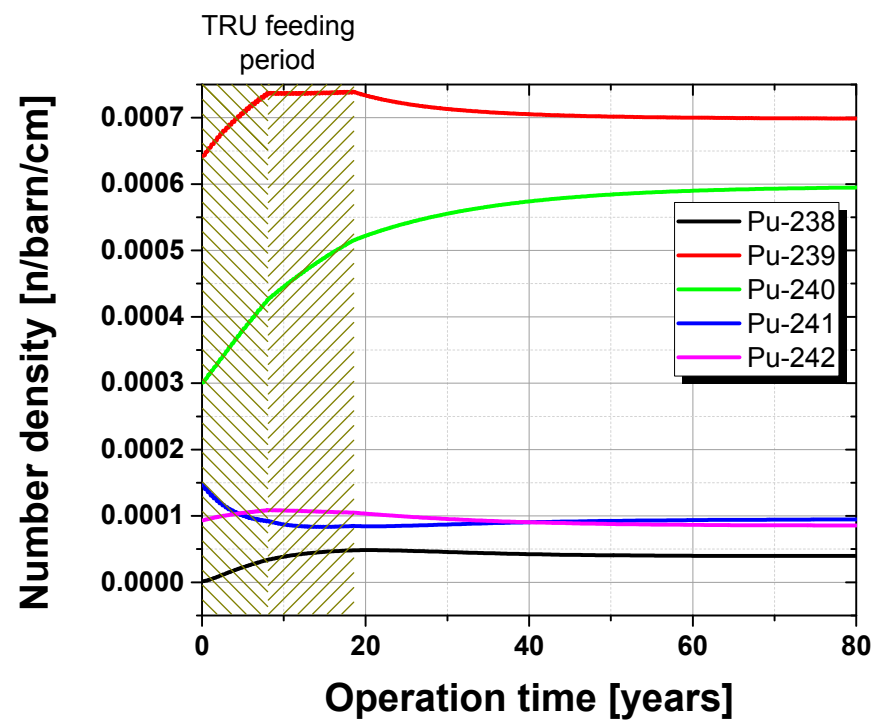

Figure 6. Number density of the different $\mathrm{Pu}$ isotope particles in the fuel salt over the observed operational period.

Table 1. The plutonium vector appearing in the reactor after long term operation compared to the $\mathrm{Pu}$ vector of the TRU used for loading.

\begin{tabular}{ccc}
\hline Isotope & Unload & Load \\
\hline $\mathrm{Pu}-238$ & $2.6 \%$ & $3.1 \%$ \\
$\mathrm{Pu}-239$ & $46.1 \%$ & $52.5 \%$ \\
$\mathrm{Pu}-240$ & $39.4 \%$ & $24.6 \%$ \\
$\mathrm{Pu}-241$ & $6.3 \%$ & $12.2 \%$ \\
$\mathrm{Pu}-242$ & $5.6 \%$ & $7.7 \%$ \\
$\mathrm{Pu} \mathrm{u}_{\text {fiss }}$ & $52.4 \%$ & $64.7 \%$ \\
\hline
\end{tabular}

\section{Discussion}

The results presented here demonstrate that a molten salt reactor with fast neutron spectrum such as that proposed in the EVOL project [29] could be operated using pure spent nuclear fuel (SNF) from light water reactors. However, some plutonium or TRU fissile material would have to be added for the initial start-up, and during transformation phase, see Figure 5. In this period, the fuel composition from the LWR has to be transformed into fuel compatible with fast reactor operation. Once this transition has occurred, solely SNF without adding any further fissile material is sufficient to keep the reactor within the iteration band of $k_{\text {eff }}$. The timescale for such transformation requires further optimization based on the core size, the initial material configuration, the feeding strategy, and the quality of the SNF used. The throughput through salt clean-up system has to be increased compared to the EVOL benchmark [30]. In the simulation here the $18 \mathrm{~m}^{3}$ of molten salt is cleaned within two cycles, corresponding to a time $\sim 250 \mathrm{~d}$.

The initial core configuration, as outlined above, $65 \% \mathrm{~mol} \mathrm{LiF}, \sim 28.5 \% \mathrm{~mol} \mathrm{SNF}$, and $\sim 6.5 \% \mathrm{TRU}$, translates to $62 \mathrm{t} \mathrm{SNF}$ and $15 \mathrm{t}$ TRU which in turn accumulate to $74 \mathrm{t}$ of HM while the blanket is filled with pure LiF salt. A comparison with data of the original EVOL benchmark configuration core: $77.5 \%$ mol LiF and 22.5\% mol HM ( 16\% Th and $\sim 6.5 \%$ TRU), blanket: $77.5 \% \mathrm{~mol} \mathrm{LiF}$ and $22.5 \% \mathrm{~mol}$ Th indicates a clear increase of the actinide content. The full EVOL reactor (core and blanket) contains $\sim 62 \mathrm{t}$ of HM compared to $74 \mathrm{t}$ of HM in the SNF core.

Over the TRU feeding period $\sim 3.6 \mathrm{t}$ of TRU are fed into the system, whereas in the evaluated operational period of 60 years $68.3 \mathrm{t}$ of SNF are fed into the system. Therefore, $\sim 69 \mathrm{t}$ of heavy metal are fed, during 60 years. For quality assurance we will compare this value with a hand calculation since 
the challenge is not only the simulation of the processes using a reactor physical tool and its validation. It is in addition the linking of all results and transferring as well as evaluating it on the level of the reactor and the long term operation. The applied procedure has already been used and improved over years leading to several publications [24-26]. However, the most reliable way to confirm a complicated process is a hand calculation based on known values:

$$
\text { burnt mass }=\text { power } \times \text { operational time } \times \text { av.consumption }
$$

where av. consumption: $42.3 \mathrm{~kg} / \mathrm{TWh}$ for a U/Pu system where no HM leaves [25], operational time: 60 years and power: $3000 \mathrm{MW}$.

The calculation leads to $66.7 \mathrm{t}$ of burnt HM providing a quick cross check of the whole procedure. Several more detailed comparisons of this style have been used to validate the procedure during development. The comparison of both values in conjunction with the change in U-238 content over the lifetime shows a slight increase in the content of major HM isotopes, confirming the quality of the very complicated and innovative simulation result.

A further parameter is to design an innovative nuclear reactor, which suppresses the misuse of plutonium as such the plutonium should be unattractive even if separated. A response to this can be seen in Table 1. In the proposed reactor system plutonium low in Pu-239 but high in Pu-240 is created, coupled with the Pu staying within the reactor until it undergoes fission. This was already highlighted in 1978 by Engel et al, as one of the most attractive features of liquid fueled reactors. Once the plutonium, or other fissile material, is put into a molten salt reactor system it is not necessary to separate the material, in order to the keep the fission process going [31]. Another important feature of such a system provides no possibility for inserting pure or almost pure fertile material for breeding-all fuel components will be mixed immediately. To create such a possibility would require a significant change in the reactor design, e.g., the core vessel. The short term insertion and irradiation of fresh fertile material, which could lead to the production and separation of plutonium by interested reactor operators or countries is almost impossible.

Reactor operation based on SNF will lead to a significantly reduced fuel cycle (see Figure 7), when compared to current nuclear reactor operation scheme and the planned operational schemes for most of the proposed Gen IV systems. No new, fresh resources are required and thus no mining which itself causes significant toxicity, "Clearly, mining is the only contributor with more than $99 \%$ of the potential impact both for the eco and the human toxicity" [32]. The reduced fuel cycle requirement and complexity lead to a strong reduction of the environmental impact from nuclear energy, since impact arising from the front end of the fuel cycle will diminish, coupled with the amounts discharged at the back end also being reduced. In the current fuel cycle tremendous amounts of material are moved. For uranium to be inserted into a French 1 GWe LWR, with a U content of $0.1 \%$ by weight 120,000 to $150,000 \mathrm{t}$ material has to move to produce the required 16 to $18 \mathrm{t}$ of enriched material to operate the reactor for one year. In contrast, in the proposed SNF operated reactor less than one ton of SNF is required to operate a $1 \mathrm{GWe}$ reactor for one year.

The arrangement of the molten salt reactor typically has co-location of reactor, salt clean-up (reprocessing), and fuel production without further transport, thus there appears no "Plutonium economy" like the current requirement for a closed fuel cycle which is based on the separation of actinides. No risky handover of $\mathrm{Pu}$ at the different stages is required. No separated fresh fertile material appears since all fuel components are immediately. However, we should not forget that the salt clean-up is a system which faces challenges close to the classical reprocessing. This process is a challenge itself, which should be re-thought in the same strictly demand driven way as part of a whole nuclear system analysis [33]. 

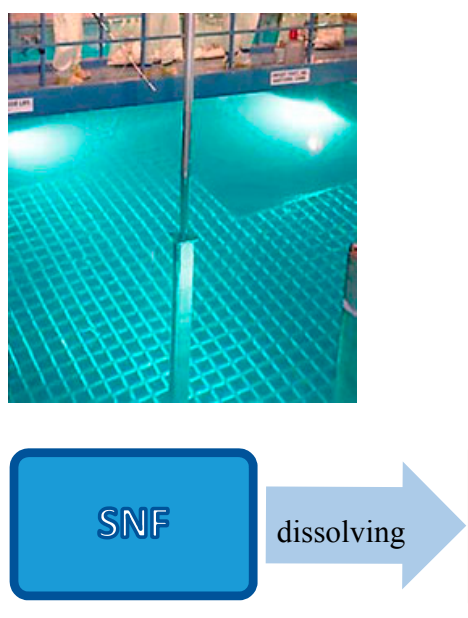

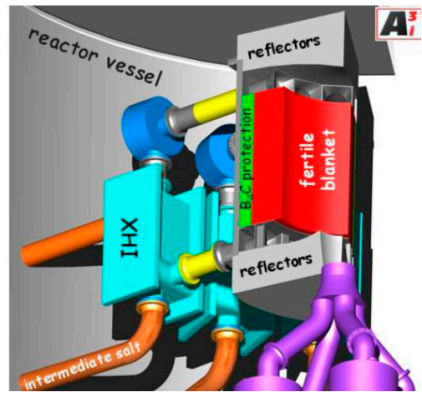

Nuclear Reactor

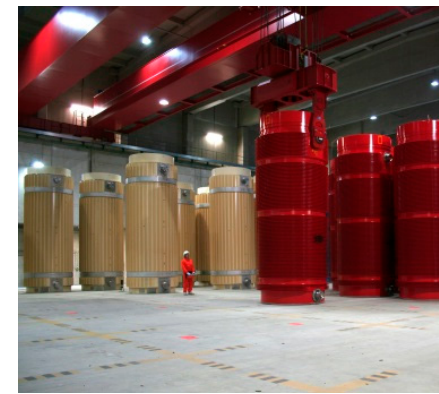

Fission Product Storage

Figure 7. The reduced fuel cycle like it would be given using MSFR fed with SNF pictures: (left): http://www.wikiwand.com/en/Spent_fuel_pool, credit DOE License: Public domain, (middle): EVOL benchmark configuration, (right): Gorleben storage hall, Origin: GNS Gesellschaft für Nuklear-Service mbH.

A comparison to classical closed fuel cycle for fast reactors (as proposed for closing the fuel cycle using classical Gen IV systems), which would be required to achieve a comparable fuel/uranium usage, is shown in Figure 8. Already components are required as input. Due to the solid nature of such fuel separate steps are required, such as the fuel production, the storage time sufficient to cool the fuel until it can be reprocessed more easily, and the reprocessing. The separation of fissile material opens possibilities for misuse, whereas the solid fuel structure opens the way to insert pure fertile material for a short irradiation to produce weapon grade materials.

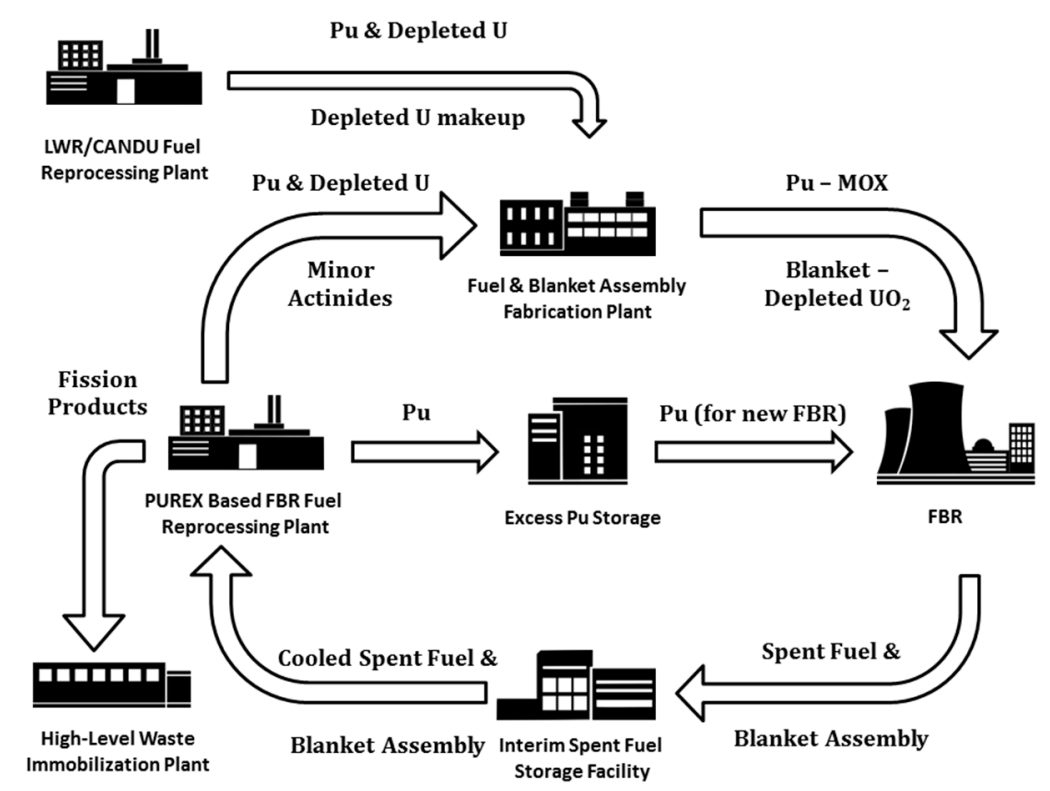

Figure 8. The classical fuel cycle like it would be given using a sodium cooled fast reactor with solid fuel for the incineration of SNF.

An almost similar fuel cycle will be required for the more advanced BREST concept of a LFR, such as that under construction in Russia. However, even the significantly more advanced processes, use 
pyro reprocessing and co-location of the fuel cycle facility like foreseen for this project [34] and suffers from the above described limitations given by the use of solid fuel.

The penultimate design parameter is a nuclear reactor which doesn't produce additional waste. Operating a reactor on SNF, the waste mass will be almost identical to SNF which is introduced into the reactor. The activity of SNF over time is indicated in Figure 9. However, the mass of waste stays the same, but 20 times more energy is produced, thus the activity of the fission products is expected to be $\sim 20$ higher (see Figure 9, red line with spheres). Consequently, besides the energy produced all requirements of waste management driving the development of Partitioning \& Transmutation (P\&T) would be fulfilled $[25,28]$ —only fission products would remain in the waste stream while all transuranic isotopes would stay in the reactor, and in turn be burnt. Hence, only the short term activity of the nuclear waste will increase when compared to the original SNF, whilst the long term activity will decrease due to the absence of TRUs in the waste. The real gain occurs however, when the result from a reactor operating on SNF is compared to the production of the same amount of energy with conventional LWRs (black line with halved squares).

However, a strategy for the handling and storage of the separated fission products from the clean-up system has to be developed. In addition to this, a strategy for the capturing and handling of volatile fission products, evaporating from the salt during reactor operation is required. Both challenges are well known in standard molten salt reactor development, with significant work already completed $[27,35,36]$. The molten salt reactor network will work in parallel designing molten salt power reactors.

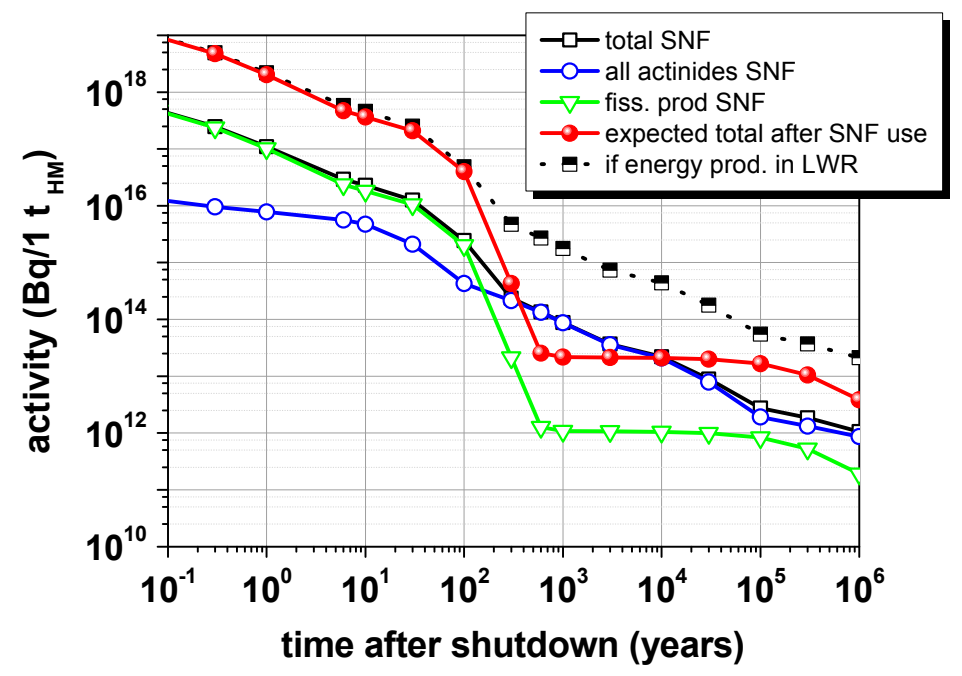

Figure 9. Activity per ton of SNF over time.

The final requirement, i.e., the reactor being both safe and financeable, with limited financial risk in both development and construction, needs to be demonstrated, challenging engineers. The design should be seen as an integrated challenge for many disciplines. It could form the first test bed applying the concept of the Integrated Nuclear Digital Environment (INDE) [37]. However, before starting such development work, and to assure that the system is working in the final design, it is essential to prove the reactor functionality regarding the operability on SNF and confirm this at each important development decision-just the ideal request for the application of INDE.

\subsection{Not an Unlimited Energy Source!}

The amount of fuel unloaded from a LWR per year has changed with time, with the increase in target burnup in LWR fuel. In 1988 the unloading amount was 27 tons per year for a 1 GWe LWR [38], 
whereas 25 years later the reported unloading mass had decreased to an annual discharge of spent fuel from a 1 GWe LWR of 19 to $20 \mathrm{t}$ at a typical burn-up of $50 \mathrm{GWd} / \mathrm{tHM}$ [39].

Depending on the discharge burnup of the LWR SNF, a MSFR utilizing LWR SNF could operate almost 20 years with SNF from one year of LWR operation. However, the initial loading of the reactor would require $\sim 62 \mathrm{t}$ of SNF, with the addition of $15 \mathrm{t}$ of separated $\mathrm{Pu}$, from $\sim 1500 \mathrm{t}$ of SNF (reprocessing $100 \mathrm{t}$ of SNF gives $\sim 1 \mathrm{t}$ of $\mathrm{Pu}$ ) in order to start the machine. However, there is a significant inventory of separated $\mathrm{Pu}$ and HEU available worldwide, with the global inventory of highly enriched uranium (HEU) estimated to be $1370 \pm 125 \mathrm{t}$, and separated plutonium of $504 \pm 10 \mathrm{t}$, of which $\sim 270 \mathrm{t}$ is available for civilian usage [40].

Combining all figures, operation of a single reactor requires less than $20 \mathrm{t}$ of seed material (TRU, $\mathrm{Pu}$, or high enriched uranium depending on the quality of the seed) and $\sim 130 \mathrm{t}$ of SNF. The amount of SNF for the initial core and 60 years of operation is produced within a LWR in less than 7 years, whilst the seed could possibly be taken from the stockpiles of $\mathrm{Pu}$ and HEU, which would then be reduced. Based on initial judgement, the amount of seed material to start up a reactor is slightly higher than for a sodium cooled fast reactor although the operational amount of seed material required is likely to be lower in the iMAGINE concept described here. It is recognized that further work would be required to understand the number of iMAGINE reactors that could be installed in a given time, fuel/seed requirements, energy output and the implications for storage and disposal of material.

With more than $320,000 \mathrm{t}$ of spent fuel in storage expected by 2020 [41], and the expectation that $\sim 130 \mathrm{t}$ are enough for 60 years of operation for a $3 \mathrm{GWth}$ reactor or $\sim 1.4$ GWe reactor, there is enough material for $\sim 2500$ reactors. If this is coupled with the expected continued use of LWRs there is plenty of energy available.

\subsection{Challenges for $R \mathcal{E} D$}

In order for such a design to be realized, and more importantly manufactured and operated several multi-disciplinary, integrative scientific and technological challenges have to be solved, which are outlined below:

Engineering:

- Optimization of burning used LWR fuel, i.e., demonstration of principles with validation

- Optimization of reactor design, i.e., better than EVOL

- Fully understanding the fluid dynamics under both normal and accidental conditions

C Componentry for molten salt system including in service inspection and repair

- Development of materials or engineering solutions capable of operating under such extreme conditions, e.g., high temperature, significant radiation damage, corrosive environment

Chemistry and Thermodynamics:

- Optimization of salt purification, i.e., removal of fission products from within the liquid phase

- Design, implementation and capture of volatile fission products, helping to keep the liquid phase pure

- Preparing the fuel—choosing the optimal method for converting used LWR fuel in to a form sufficient for use within the reactor

- Appreciation of the chemical thermodynamics, and limitations in using molten salts with high levels of actinide loading

Safety:

- Develop the safety methodology and implementation protocols for such a novel liquid reactor design

- Assurance in safety of such a co-located site, i.e., both reactor and reprocessing 
Others:

- Economic viability, ensuring the reactor is economically viable and competitive with current technology

- Ensure the public acceptance of such a new technology, without which the reactor is unviable

- Development, verification, and validation of an integrated computer simulation environment incorporating reactor physics, salt chemistry, process engineering, thermodynamics, and material behavior

A detailed look into these challenges makes clear, these are worth a long term (international) research program to be solved. The maturity level of most of the technologies is in technical readiness level (TRL) 1 to 3 . However, this could create the basis for a long term success of nuclear reactors as a major carbon free, sustainable, and applied highly reliable energy source.

Besides the above challenges there remain other hurdles to overcome, as a consequence a step by step approach is foreseen gaining operational experience, such that further developments can be made. Starting in a manner similar to the development of previous reactors hopefully with more modelling and simulation as well as digital design. Nevertheless, a small low power experimental machine should be initiated, which would lead on improved implementable designs. Such a machine has to be planned, built, and financed [25]. However, there is experience on other practical challenges available from the EVOL project, there are already proposals made and published on solving the very high neutron fluences on safety related structures [42].

\section{Materials and Methods}

The raw data of the calculations and the used PYTHON script are available under [43].

\subsection{Reference Configuration}

The calculations are based on the core dimensions and boundary conditions given in the EVOL benchmark definition (see Figure 10), and focus on a reference MSFR of 3000 MWth using a fast neutron spectrum The reactor core is a single cylinder with flowing fuel salt within [30], the dimensions shown in Figure 10. The whole core system is composed of four volumes, an active core, an upper extraction area, a lower injection area, and outside the core where the heat exchanger and pumps are. The active core is surrounded by a blanket ring, and a protection ring, both made from absorbing material, with both components having the function of protecting the pumps and heat exchanger from the high neutron flux arising within the active core.
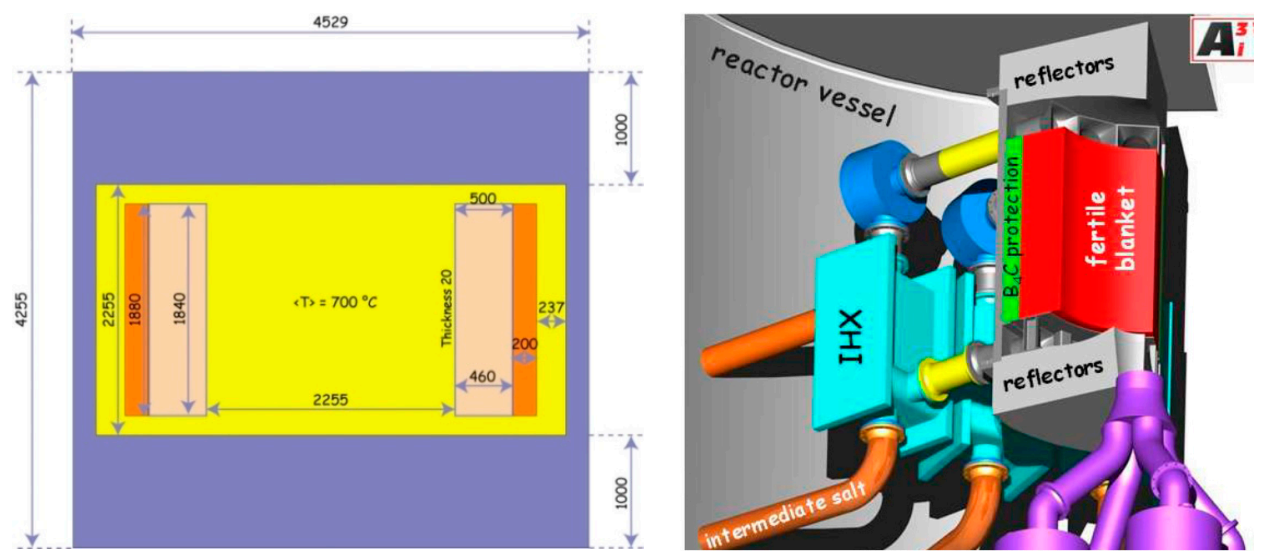

Figure 10. (Right): Simplified scheme of the MSFR system including the core, blanket and heat exchangers (IHX)—(Left): Benchmark definition [30]. 
The spent nuclear fuel composition, used in this analysis, is based on material and geometry of the “OECD/NEA AND U.S. NRC PWR MOX/UO2 CORE TRANSIENT BENCHMARK" [44]. The uranium oxide fuel assembly, with $4.5 \%$ enrichment in U-235, has been calculated to a maximum burnup of $50 \mathrm{GWd} / \mathrm{tHM}$ using HELIOS 2.1 to approximate the model material configuration. To simulate storage time leading to $\mathrm{Pu}-241$ decay, the $\mathrm{Pu}-241$ content has been halved and turned to $\mathrm{Am}-241$, equivalent to a postulated storage of 14 years. Besides this change no further adaption for storage has been introduced, which can be considered a conservative assumption from a neutronic point of view. For the initial addition of fissile material for reactor start-up the TRU isotopic vector given in Table 2 is used, and follows the definition of the EVOL benchmark.

Table 2. Used transuranium (TRU) isotopic vector-EVOL benchmark data [30].

\begin{tabular}{cc}
\hline Isotope & Concentration \\
\hline $\mathrm{Np} 237$ & $6.30 \%$ \\
$\mathrm{Pu} 238$ & $2.70 \%$ \\
$\mathrm{Pu} 239$ & $45.90 \%$ \\
$\mathrm{Pu} 240$ & $21.50 \%$ \\
$\mathrm{Pu} 241$ & $10.70 \%$ \\
$\mathrm{Pu} 242$ & $6.70 \%$ \\
$\mathrm{Am} 241$ & $3.40 \%$ \\
$\mathrm{Am} 243$ & $1.90 \%$ \\
$\mathrm{Cm} \mathrm{244}$ & $0.80 \%$ \\
$\mathrm{Cm} 245$ & $0.10 \%$ \\
\hline
\end{tabular}

The salt configuration is also based on the EVOL benchmark, and consists of $\mathrm{LiF}_{\text {with }}$ mainly $\mathrm{UF}_{4}$ (calculated as $\mathrm{SNFF}_{4}$ as approximation). However, in contrast to the EVOL benchmark, the share of SNF has to be determined, to allow for sufficient breeding of fissile material keeping the reactor critical for long term operation without further feeding of fissile material. The blanket region is filled with pure $\mathrm{LiF}_{4}$. The overall fuel salt volume is $18 \mathrm{~m}^{3}$ within the core and $7.7 \mathrm{~m}^{3}$ within the blanket. The salt clean up system has been defined in the EVOL benchmark with a clean-up time of $\sim 450 \mathrm{~d}$ for the full amount of $18 \mathrm{~m}^{3}$ fuel salt. This value has to be adapted, thus provides an additional degree of freedom for the optimization of the breeding.

\subsection{Modelling and Calculation Tool}

For the model evaluations, the HELIOS 2.1 licensing grade code system is used with the internal 177 group library [45]. The HELIOS code is a 2D spectral code with wide unstructured mesh capabilities and a transport solver, based on the collision probability method [46]. The benchmark configuration is transferred to a volume corrected 2D HELIOS model (see Figure 11). The leakage in the third dimension has been fixed based on 3D calculations within the EVOL benchmark exercises, while the leakage in radial direction is directly modelled. Additionally, the model has been adapted to improve the representation of the 16 heat exchanger pipes instead of the smeared treatment in the benchmark configuration. 


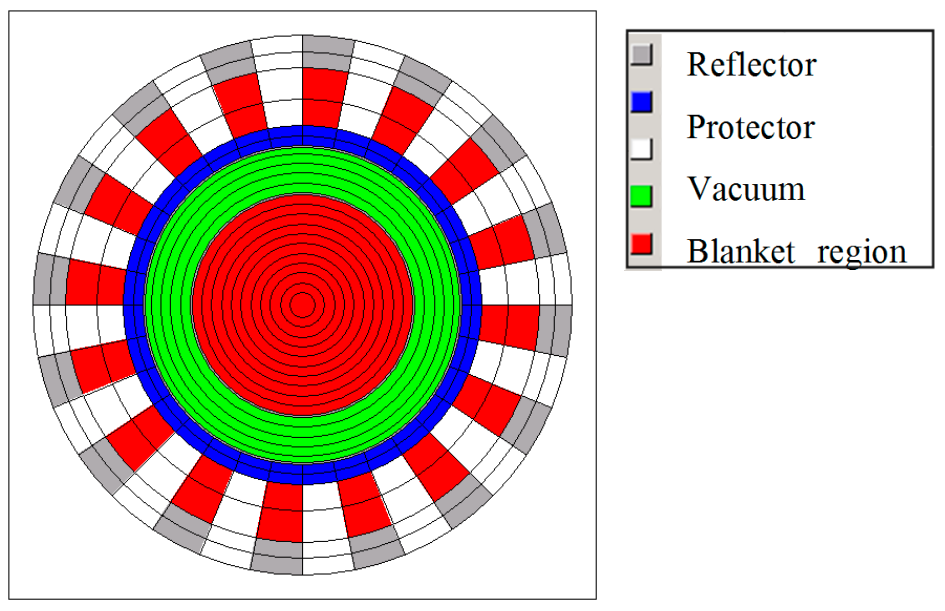

Figure 11. Volume corrected 2D HELIOS model of the molten salt reactor.

The HELIOS code is an industrial standard software which performs the neutron transport calculation, the burn up calculation, and if requested the cross section. Originally, as HELIOS was written for the simulation of solid fuel assemblies, i.e., as used for the determination of a SNF configuration. The possibility of online refueling and online salt clean-up is not foreseen. To deal with these special features of molten salt reactors a PYTHON script has been developed, based on the features of the HELIOS package. All information, which is constant during the whole reactor operation, is stored in a so-called expert input, while the changing material configuration is given in the user input, which is written new in every cycle using the PYTHON script. Within each cycle 5 burnup steps are calculated in HELIOS to the target burnup of $5000 \mathrm{MWd} / \mathrm{tHM}$. Both inputs are merged in the pre-processor code AURORA, which creates the updated input for the HELIOS, determining neutron flux distribution and burnup of material. The results are finally evaluated for each cycle in the post-processor ZENITH, where it is decided which isotopes will be fed back into the next user input, created with the help of the PYTHON script (see Figure 12). Theoretically, it is possible to simulate a molten salt reactor precisely by using small time steps in this calculation loop. However, in a real MSR two different time scales for salt clean-up can be observed, due to the different extraction methods for fission products. These are helium bubbling for gaseous and volatile fission products with a comparably short operation cycle (minutes), and online salt clean-up for dissolved fission products with a significantly longer operation cycle. To simulate these different time scales a full removal of gaseous and volatile fission products takes place after each $5000 \mathrm{MWd} / \mathrm{tHM}$ cycle, but only a partial removal of dissolved fission products is established at the end of cycle. The lower efficiency in the separation of lanthanides is considered by a $20 \%$ lower reduction than for the other dissolved fission products. The throughput of the $18 \mathrm{~m}^{3}$ salt is an optimization parameter, which needs to be determined. However, what is most likely is that throughput through the salt cleanup system will have to be increased when compared to the EVOL benchmark, due to the fission products which are inserted with the SNF.

Due to the characteristics of HELIOS, some approximations have to be accepted, for example, there is no fuel salt movement, thus an undesired burnup distribution arises during the calculation cycle, and the materials are only re-distributed when a new user input is defined via the script. As HELIOS was designed for use with LWR reactors, a LWR spectrum is used for the within group weighting of the 177 group master libraries. However, comparisons to SERPENT on the isotope accumulation during the burnup in a fast reactor configuration using different HELIOS libraries (HELIOS 1 and HELIOS 2) have shown an acceptable agreement for major isotopes [47]. Additionally, different versions of the HELIOS 1 code have been used in the EVOL benchmark calculations for MSFRs [48] and in the benchmark calculations in the ESNII+ project for SFR [49]. In both benchmarks the results were comparable to the other codes, with no major systematic discrepancies observed. 
A significant improvement has been observed for the use of HELIOS 2 with the cross section libraries based on the most advanced ENDF/B VII library system, and the approximations and use of the HELIOS code package seems to be adequate for the level required for this kind of long term feasibility study. The major uncertainties are predominantly given by the current preliminary design which is far from optimized, with a more detailed design required for the next phase. Such design uncertainties are expected to impact significantly more to the uncertainties than the approximations made within the modelling and the applied code. In general the calculations are performed to demonstrate the feasibility of such operation of a critical reactor on the basis of spent LWR fuel with high burnup.

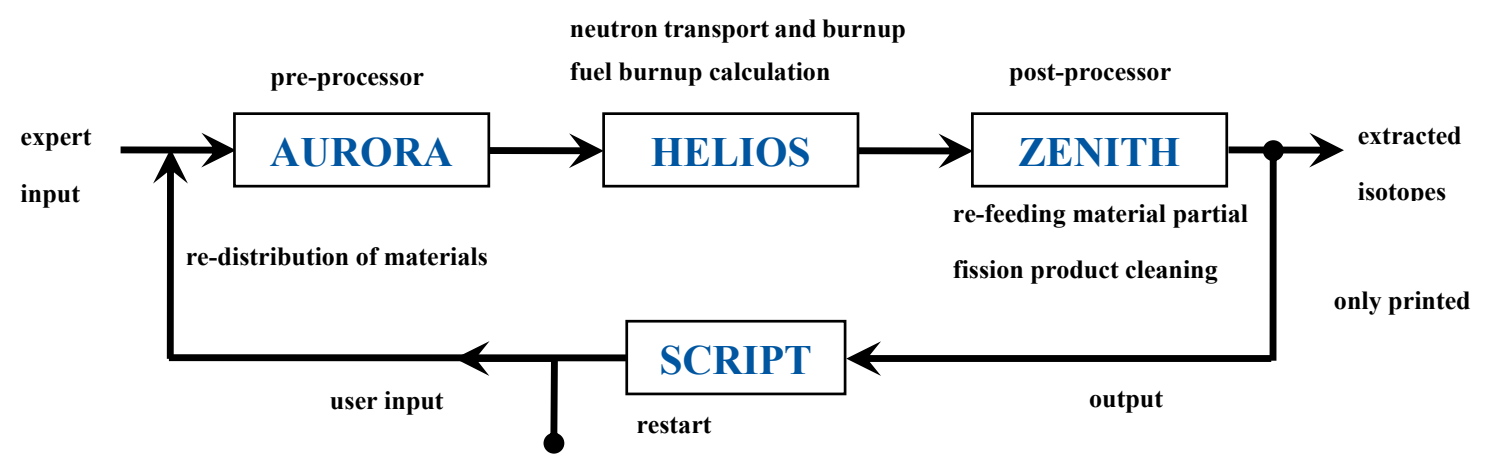

Figure 12. Description of the calculation cycle for the simulation of a MSR.

\section{Conclusions}

Invention and innovation in nuclear reactor development can be described with the concept of developments in S-curves. The identified key points which should drive invention and innovation are the changed boundary conditions, and the evolvable objectives. These new objectives ideally coincide with the ultimate, universal vision for energy production characterized by minimal use of resources and production of waste, while being economically affordable and safe, secure and reliable in operation.

Following these objectives, a new innovative proposal has been shown, whose operation is based on utilizing spent nuclear fuel (SNF) from light water reactors (LWRs) as the main fuel, fulfilling the goals of sustainability in innovative electric energy production. A proof of the feasibility is provided based on a reactor neutronics point of view which provides a solution to the major challenge, establishing a breeding process which generates sufficient fissile material from the inserted SNF. For the initiation of the system a support of fissile material in the initial core and during a transition phase is required. Optimization of the design should be performed defining an ideal initial composition, and the required efficiency of the salt purification system, leading to a further objective of minimizing the time required for the transition from a system fed with fissile material and SNF to a pure SNF feed.

The result of such a design would be a system which does neither require new resources nor produce additional waste, providing an option of a sustainable future nuclear system. In addition to providing the desired sustainability, the partitioning \& transmutation requirements for such an innovative waste management strategy would be fulfilled in this system as an advantageous side effect. In addition, it provides enhanced resistance against misuse of $\mathrm{Pu}$ arising from a high $\mathrm{Pu}-240$ content, with a very limited possibility for short time insertion fertile material, coupled with $\mathrm{Pu}$ remaining in the system without further separations. The sustainability of such a system is supported by the significantly reduced environmental impact of the fuel cycle, which is reduced to 3 steps, i.e., dissolving the SNF, reactor operation, storage of fission products. Thus today's front end of the fuel cycle consisting of mining, conversion, and enrichment would no longer be required, eliminating a major source of toxicity arising from the mining/extraction process.

The use of SNF from LWR as reactor fuel would additionally open a vast energy resource of almost 2500 reactors, each 1.4 GWe operating for 60 years based on the SNF masses postulated for 
2020. Thus this design would provide a significant, but not infinite, amount of energy. The design requirement of such an innovative system would be safe and financeable with limited financial risk in both development and construction, is a challenge which should ideally be tackled by an international consortium following the proposal of the integrated nuclear data environment [37]. The ideal consortium would consist of all countries with an interest in solving their SNF problem. The development of such a sustainable and innovative nuclear reactor is a major challenge across engineering, but with a substantial impact on the future of the worldwide energy production.

Acknowledgments: The main author wants thank the Royal Academy of Engineering and the National Nuclear Laboratory for creating and sponsoring the research chair position which creates the opportunity for free thinking and working on freely defined topics for the progress of science.

Author Contributions: Bruno Merk designed the work, provided calculations, evaluations, wrote and co-ordinated the manuscript; Dzianis Litskevich provided calculations, evaluations and scripts; Karl R. Whittle supported writing the manuscript and contributed to the discussion; Mark Bankhead co-designed the work, supported writing the manuscript and contributed to the discussion; Richard J. Taylor motivated the work, supported writing the manuscript and contributed to the discussion; Daniel Mathers supported writing the manuscript and contributed to the discussion.

Conflicts of Interest: The authors declare no conflict of interest.

\section{Abbreviations}

\begin{tabular}{|c|c|}
\hline MSR & Molten Salt Reactor \\
\hline MSFR & Molten Salt Fast Reactor \\
\hline LWR & Light Water Reactor \\
\hline iMAGINE & Visionary Molten Salt Fast Reactor Concept operating on spent nuclear fuel \\
\hline SNF & Spent Nuclear Fuel \\
\hline TRU & Transuranium—all elements with an atomic number higher than 92 \\
\hline $\mathrm{HM}$ & $\begin{array}{l}\text { heavy metal-all elements with an atomic number higher than } 90 \text {, typically the base to } \\
\text { account for fissile materials in the reactor }\end{array}$ \\
\hline HEU & Highly enriched Uranium—typically uranium with more than $20 \%$ U-235 content \\
\hline MWth & Megawatt thermal \\
\hline GWe & Gigawatt electric \\
\hline GWd/tHM & Gigawattdays per ton of heavy metal-measure for the burnup of nuclear material in a reactor \\
\hline $\mathrm{MWd} / \mathrm{tHM}$ & Megawattdays per ton of heavy metal \\
\hline GenIV & Reactor systems of the 4 th generation as defined by the Generation IV International Forum \\
\hline NEA & Nuclear energy Agency of the OECD \\
\hline IAEA & International Atomic Energy Agency of the United Nations \\
\hline$\Delta$ keff & difference from the critical reactor status, typically measured in pcm (percent mille) \\
\hline $\mathrm{LiF}$ & Lithiumfluoride \\
\hline SNFF4 & Spent Nuclear Fuel Tetrafluoride \\
\hline UF4 & Uranium Tetrafluoride \\
\hline EVOL & European project for the development of a molten salt fast reactor \\
\hline BREST & Russian innovative reactor concept with lead coolant \\
\hline INDE & Integrated Nuclear Digital Environment \\
\hline R\&D & Research and Development \\
\hline TRL & Technical readiness level \\
\hline HELIOS & Reactor physics code package of Studsvik Scandpower \\
\hline AURORA & pre-processor of the HELIOS package \\
\hline ZENITH & post-processor of the HELIOS package \\
\hline SERPENT & Reactor physics package based on the Monte Carlo method \\
\hline ENDF/B VII & Nuclear data library \\
\hline
\end{tabular}

\section{References}

1. Rogers, E.M. Diffusion of Innovations, 5th ed.; Paperback; Free Press: New York, NY, USA, 2003. 
2. Malik, F. Strategy-Navigating the Complexity of the World; Campus Verlag: Frankfurt, Germany; New York, NY, USA, 2013.

3. A History of the World: The World's First Lawnmower. Available online: http://www.bbc.co.uk/ ahistoryoftheworld/objects/NI2ZjBwpTcqYdtpXFnIzUQ (accessed on 23 June 2017).

4. Achievements: Reactors Designed by Argonne National Laboratory. Available online: http://www.ne.anl. gov/About/reactors/early-reactors.shtml (accessed on 6 April 2016).

5. Technology Roadmap Update for Generation IV Nuclear Energy Systems, January 2014. Available online: https://www.gen-4.org/gif/upload/docs/application/pdf/2014-03/gif-tru2014.pdf (accessed on 6 April 2016).

6. World Energy Council: Energy Trilemma Index. Available online: https://trilemma.worldenergy.org/ (accessed on 5 April 2017).

7. Outline History of Nuclear Energy. (Updated March 2014). Available online: http:/ /www.world-nuclear. org/information-library/current-and-future-generation/outline-history-of-nuclear-energy.aspx (accessed on 7 April 2016).

8. Hyman, G. Rickover. Available online: http://www.globalsecurity.org/military/agency/navy/rickover.htm (accessed on 5 April 2017).

9. Roehrlich, E. 60 Years of "Atoms for Peace". Available online: https://www.iaea.org/newscenter/news /60years-atoms-peace (accessed on 21 June 2016).

10. Eisenhower, D.D. Atoms for Peace Speech, 470th Plenary Meeting of the United Nations General Assembly. Available online: https://www.iaea.org/about/history/atoms-for-peace-speech (accessed on 24 May 2017).

11. Nash, K.L.; Nilsson, M. Introduction to the Reprocessing and Recycling of Spent Nuclear Fuels. In Reprocessing and Recycling of Spent Nuclear Fuel; Taylor, R., Ed.; Woodhead Publishing Series in Energy 79; Elsevier: Oxford, UK, 2015.

12. Barnham, K.W.J.; Hart, D.; Nelson, J.; Stevens, R.A. Did civil reactors supply plutonium for weapons? Nature 2000, 407, 833-834. [CrossRef] [PubMed]

13. Barnham, K.W.J.; Hart, D.; Nelson, J.; Stevens, R.A. Production and destination of British civil plutonium. Nature 1985, 317, 213-217. [CrossRef]

14. RBMK Reactors. Available online: http://www.world-nuclear.org/information-library/nuclear-fuel-cycle/ nuclear-power-reactors/appendices/rbmk-reactors.aspx (accessed on 15 June 2016).

15. Cerullo, N.; Lomonaco, G. Generation IV reactor designs, operation and fuel cycle. In Nuclear Fuel Cycle Science and Engineering; Crossland, I., Ed.; Woodhead Publishing Limited: Cambridge, UK, 2012; pp. $333-395$. [CrossRef]

16. Carré, F. The Nuclear Fuel Cycle: Key to Generation IV Nuclear Energy Systems' Sustainability and Transition from LWRs, ANS Annual Meeting. Available online: http://web.mit.edu/nse/pdf/news/ 2007/07_ansannualmtg/ANS_07\%20(Carre).pdf (accessed on 5 May 2017).

17. Trends towards Sustainability in the Nuclear Fuel Cycle; NEA No. 6980; Nuclear Development: Paris, France, 2011.

18. Assessment of Nuclear Energy Systems Based on a Closed Nuclear Fuel Cycle with Fast Reactors; A Report of the International Project on Innovative Nuclear Reactors and Fuel Cycles (INPRO), IAEA-TECDOC-1639; International Atomic Energy Agency: Vienna, Austria, 2010.

19. Merk, B.; Stanculescu, A.; Chellapandi, P.; Hill, R. Progress in reliability of fast reactor operation and new trends to increased inherent safety. Appl. Energy 2015, 147, 104-116. [CrossRef]

20. MacPherson, H.G. The Molten Salt Reactor Adventure. Nucl. Sci. Eng. 1985, 90, 374-380. [CrossRef]

21. Myung-Seung, Y.; Choi, H.B.; Jeong, C.J. The status and prospect of DUPIC fuel technology. Nucl. Eng. Technol. 2006, 38, 359-374.

22. Wigeland, R.; Taiwo, T.; Ludewig, H.; Todosow, M.; Halsey, W.; Gehin, J.; Jubin, R.; Buelt, J.; Stockinger, S.; Jenni, K.; et al. Nuclear Fuel Cycle Evaluation and Screening-Final Report, INL/EXT-14-31465, FCRD-FCO-2014-000106. Available online: https:/ fuelcycleevaluation.inl.gov/Shared\%20Documents/ES\% 20Main\%20Report.pdf (accessed on 24 May 2017).

23. Kim, T.K.; Taiwo, T.A.; Wigeland, R.A.; Dixon, B.W.; Gehin, J.C.; Todosow, M. Mass Flow Data Comparison for Comprehensive Fuel Cycle Options. In Proceedings of the Actinide and Fission Product Partitioning and Transmutation Thirteenth Information Exchange Meeting, Seoul, Korea, 23-26 September 2014. 
24. Merk, B.; Rohde, U.; Glivici-Cotruta, V.; Litskevich, D.; Scholl, S. On the Molten Salt Fast Reactor for Applying an Idealized Transmutation Scenario for the Nuclear Phase Out. PLoS ONE 2014, 9, e92776. [CrossRef] [PubMed]

25. Merk, B.; Litskevich, D. Transmutation of All German Transuranium under Nuclear Phase out Conditions-Is This Feasible from Neutronic Point of View? PLoS ONE 2015, 10, e0145652. [CrossRef] [PubMed]

26. Merk, B.; Litskevich, D. On the Burning of Plutonium Originating from Light Water Reactor Use in a Fast Molten Salt Reactor-A Neutron Physical Study. Energies 2015, 8, 12557-12572. [CrossRef]

27. EVOL (Project No. 249696) FINAL REPORT. Available online: http://cordis.europa.eu/docs/results/249/ 249696/ final1-final-report-f.pdf (accessed on 23 June 2017).

28. Acatech. Partitioning and Transmutation of Nuclear Waste. Opportunities and Risks in Research and Application; Acatech POSITION PAPER; Acatech: Munich, Germany, 2014.

29. Final Report Summary_EVOL (Evaluation and Viability of Liquid Fuel Fast Reactor System). Available online: http:/ / cordis.europa.eu/result/rcn/159411_en.html (accessed on 5 May 2017).

30. Molten Salt Fast Reactor, EVOL Reference Configuration. Available online: http://cordis.europa.eu/docs/ results /249/249696/final1-final-report-f.pdf (accessed on 23 June 2017).

31. Engel, J.R.; Grimes, W.R.; Rhoades, W.A.; Dearing, J.F. Molten-Salt Reactors for Efficient Nuclear Fuel Utilization Without Plutonium Separation, ORNL/TM-6413, August 1978. Available online: http:/ / web. ornl.gov/info/reports/1978/3445603227167.pdf (accessed on 15 July 2015).

32. Poinssot, Ch.; Bourg, S.; Ouvrier, N.; Combernoux, N.; Rostaing, C.; Vargas-Gonzalez, M.; Bruno, J. Assessment of the environmental footprint of nuclear energy systems. Comparison between closed and open fuel cycles. Energy 2014, 69, 199-211. [CrossRef]

33. Merk, B.; Litskevich, D.; Bankhead, M.; Taylor, R.J. An Innovative Way of Thinking Nuclear Waste Management-Neutron Physics of a Reactor Directly Operating on SNF, OECD/NEA Actinide and Fission Product Partitioning and Transmutation. In Proceedings of the 14th Information Exchange Meeting, Hilton San Diego Mission Valley, San Diego, CA, USA, 17-20 October 2016.

34. Adamov, E.O.; Pershukov, V.A. Project Proryv (Breakthrough). In Proceedings of the VII International Forum ATOMEXPO, Moscow, Russia, 30 May 2016.

35. Ignatiev, V.; Feynberg, O.; Merzlyakov, A.; Surenkov, A.; Zagnitko, A.; Afonichkin, V.; Bovet, A.; Khokhlov, V.; Subbotin, V.; Fazilov, R.; et al. Progress in Development of MOSART Concept with Th Support. In Proceedings of the 2012 International Congress on Advances in Nuclear Power Plants (ICAPP'12), Chicago, IL, USA, 24-28 June 2012.

36. Safety Assessment of the Molten Salt Fast Reactor. Available online: http://samofar.eu/ (accessed on 23 June 2017).

37. Patterson, E.A.; Taylor, R.J.; Bankhead, M. A framework for an integrated nuclear digital environment. Prog. Nucl. Energy 2016, 87, 97-103. [CrossRef]

38. Madic, C. From the Reactor to Waste Disposal: The Back-End of the Nuclear Fuel Cycle, Biological Assessment of Occupational Exposure to Actinides, Versailles, France, 1988. Available online: http: //www.iaea.org/inis/collection/NCLCollectionStore/_Public/20/005/20005325.pdf?r=1 (accessed on 18 April 2016).

39. Feiveson, H.; Mian, Z.; Rama, M.V.; von Hippel, F. Spent Fuel from Nuclear Power Reactors-An Overview of a New Study in the International Panel on Fissile Materials, Draft for Discussion. June 2011. Available online: http:/ fissilematerials.org/library/ipfm-spent-fuel-overview-june-2011.pdf (accessed on 18 April 2016).

40. Fissile Material Stocks, International Panel on Fissile Materials. Available online: http://fissilematerials.org/ (accessed on 18 April 2016).

41. Costing of Spent Nuclear Fuel Storage, IAEA Nuclear Energy Series Technical Reports No. NF-T-3.5, IAEA 2009. Available online: https://www.iaea.org/sites/default/files/costingfuel0909.pdf (accessed on 30 August 2016).

42. Merk, B.; Konheiser, J. Shielding Studies on an Advanced Molten Salt Fast Reactor Design. Ann. Nucl. Energy 2014, 64, 441-448. [CrossRef]

43. Merk, B. Molten Salt Reactor Study. Available online: http://datacat.liverpool.ac.uk/id/eprint/151 (accessed on 23 June 2017). 
44. Kozlowski, T.; Downar, T.J. OECD/NEA AND U.S. NRC PWR MOX/UO2 Core Transient Benchmark. OECD NEA, Final Spec. 2003. Available online: http:/ /www.nea.fr/science/wprs/MOX-UOX-transients/ benchmark_documents/specifications/mox_bench_spec.pdf (accessed on 23 June 2017).

45. HELIOS-2 Methods, Version 2.1; SSP-11/452 Rev 1; Studsvik Scandpower: Waltham, MA, USA, 2011.

46. Villarino, E.A.; Stammler, R.J.J.; Ferri, A.; Casal, J.J. HELIOS: Angularly dependent collision probabilities. Nucl. Sci. Eng. 1992, 112, 16-31. [CrossRef]

47. Rachamin, R.; Wemple, C.; Fridman, E. Neutronic analysis of SFR core with HELIOS-2, Serpent, and DYN3D codes. Ann. Nucl. Energy 2013, 55, 194-204. [CrossRef]

48. Brovchenko, M. Neutronic Benchmark of the Molten Salt Fast Reactor in the Frame of the EVOL and MARS Collaborative Projects. Ann. Nucl. Energy 2015. submitted.

49. Mikityuk, K. Core Safety (ESNII + WP6). In Proceedings of the European Nuclear Gen II, III, IV Days, Brussels, Belgium, 17-19 March 2015.

(C) 2017 by the authors. Licensee MDPI, Basel, Switzerland. This article is an open access article distributed under the terms and conditions of the Creative Commons Attribution (CC BY) license (http://creativecommons.org/licenses/by/4.0/). 